\title{
The analysis and validation of landform stability using unmanned aerial vehicles
}

\author{
J Kelcey Astron Environmental Services, Australia \\ D Blaxland Gold Fields Australia Pty Ltd., Australia \\ B Smith Astron Environmental Services, Australia \\ A Gove Astron Environmental Services, Australia
}

\begin{abstract}
Mine closure relies on proof of best practice in both design and performance of rehabilitation. Field techniques have been the traditional approach for producing detailed supporting empirical evidence for mine closure. Although field sampling provides a detailed snapshot of key performance criteria within small areas, these areas themselves may not be representative of the overall performance of rehabilitation. Additionally, their limited scale may miss broader spatial characteristics that could further strengthen arguments for relinquishment. Remote sensing is a complimentary approach to field sampling that can produce an entire census of a rehabilitation site at a reduced scale. However, uncertainty still surrounds the adoption of a remote sensing approach, and whether such techniques can capture key performance indicators accurately and consistently.

This paper provides both a demonstration of capacity, and quantification of accuracy, of remotely sensed data analytics for the production of empirical evidence to support mine closure management. Using rehabilitated landforms in the Western Australian Goldfields as case studies, remote sensing was adopted in two supporting roles: the validation of landform construction, and the ongoing monitoring of landform performance. The geometry of constructed landform surfaces was measured through photogrammetric techniques and assessed against design specifications. Ongoing monitoring assessed both vegetative colonisation and relative stability of established landform surfaces. Coupled together, the broader scale impact of non-compliant areas upon local rehabilitation performance was explored and discussed.

Underpinning these data analytics is the accuracy of remotely sensed data. The quantification of uncertainty within the data was derived through a comparison against precision field measurements. Quantification of this uncertainty allowed the establishment of confidence intervals on derived measurements. Furthermore, the impact of changing environmental complexity upon analysis performance was quantified. This allowed for the modelling of compensation factors that dynamically counterbalance the increased uncertainty of complex environments. The result of the study demonstrates the capacity for a remote sensing approach to empirically support mine closure and relinquishment.
\end{abstract}

Keywords: rehabilitation, mine closure, unmanned aerial vehicles, remote sensing, gully, erosion, criteria

\section{Introduction}

Mine closure is reliant upon the construction of waste rock landforms (WRLS) that are both physically and chemically safe, stable and non-polluting. Potential for erosion is of significant concern in WRL design. Poorly designed geometry and topography may concentrate and accelerate water flow, leading to increased surface erosion and gully formation. Without early intervention, gullying may expose previously covered, geochemically and geotechnical sensitive materials which may include potentially acid forming, highly erosive or naturally occurring radioactive materials. This is turn may undermine landform stability or leach ecologically harmful materials into the surrounding environment. 
Early intervention is dependent upon assessing the overall stability of a WRL, and assessing the factors that undermine landform stability. Field based techniques have been the traditional approach for the long-term monitoring and quantifying key indicators such as gullying. A basic field survey may involve simple traverses of a landform to qualitatively assess its condition. Objective, empirical evidence is essential, however, when modelling the likely trajectory of WRL stability. Such evidence has been traditionally gathered through field sampling techniques, which encompass both, transects and quadrat-based surveys. However, time and resources may place constraints on how many field sampling sites can be established and monitored. This in turn affects the representativeness of the broader spatial characteristics of a WRL, as well as having the potential to miss important key features or events that may develop outside of sampling areas. Remote sensing offers a complimentary approach to field sampling that can quantify the entire state of a WRL.

Remote sensing is the science of measuring properties of a phenomenon, object or geographic area without physical contact. Remote sensing typically employs a range of mobile platforms outfitted with sensor systems. The variety of sensor systems is wide, with measuring capabilities covering a broad range of spectral and structural characteristics. The deployment of satellite and airborne platforms for remote sensing is an established mature science, and the platforms are utilised for a range of monitoring purposes. Ma et al. (2018) utilised Landsat satellite data for broad scale hydrological modelling of the Shehong basin in China. Thermal imaging of the Mt Etna volcanic activity was analysed by Ganci et al. (2018) using the MODIS HOTSAT system. Housman et al. (2018) compared and contrasted a range of platforms for the broad scale assessment of vegetation condition. The growing capacity of satellite remote sensing to both quantify and map heat island effects within urbanised areas was assessed by Zhou et al. (2019).

The detection and measurement of WRL gullying is constrained by the spatial resolution of the data, and therefore its capacity to model local topographic structure. This limits satellite and airborne platforms to the detection of large, established gullies. Early intervention requires the identification and measurement of emerging gullies, which in turn requires data with ultra-high spatial resolution data. The unmanned aerial vehicle (UAV) represents a relatively new class of remote sensing platform that is capable of capturing ultra-high spatial resolution data required for the accurate characterisation of gullies.

The successful implementation of UAV remote sensing has frequently been demonstrated within scientific literature. Deng et al. (2018) explored a range of UAV-based multispectral sensors for precision agriculture monitoring. The combined effects of micro-topography and water availability upon sub-Antarctic moss beds were explored by Lucieer et al. (2014) using a precision UAV survey. A machine learning approach to UAV image classification was utilised by Feng et al. (2015) to map urban vegetation. Guo et al. (2017) explored the potential for forest habitat mapping using 3D data captured from a UAV-based lidar system. UAVs offer several advantages over satellite and airborne platforms. A low operational altitude captures data of an ultra-high spatial resolution unmatched by other platforms. Furthermore, their capacity for rapid deployment and fly-on-demand characteristics can both produce high temporal resolution datasets as well as exploit small, limited windows of opportunity. UAVs however, face limitations when dealing with large spatial expanses and heavy payloads. The power constraints of UAVs limit both flight speed and time, which in turn limit the spatial extents that can be captured within a reasonable time frame. The limitation in payload capacity has a direct influence upon data quality, as miniaturisation may require the removal of onboard features that compromise sensor quality for weight.

Despite these limitations, the UAV is ideally placed as a remote sensing platform for detailed captures of WRLs. With skilled flight planning and piloting, the UAV is capable of performing high precision aerial surveys. As low-cost drones can be kept onsite, they can be quickly and effectively deployed to capture a range of useful spectral and topographic information. Such a census provides a detailed snapshot of the external condition of the WRL that includes the state of geometric shape and vegetation cover. With repeated captures at key times, the trajectory of performance characteristics can be modelled and assessed.

Despite the potential of remote sensing to quantitatively complement field surveys, uncertainty still surrounds the adoption of a remote sensing approach. In particular, there remains concern on whether 
such techniques can capture key performance indicators both accurately and consistently. Quantification of the uncertainty within the captured data is key to justifying the broader uptake of a remote sensing methodology for rehabilitated landform analysis. This study aims to address those concerns through the discussion and quantification of this uncertainty. As part of this exploration, the factors impacting the accuracy of gully analysis are explored, including the potential benefit of modelling and controlling such factors. The result of the study demonstrates the capacity for a remote sensing approach to empirically support mine closure and relinquishment.

\section{Methodology}

\subsection{Study site}

To compare and contrast the UAV data acquisition and analysis, data were collected from two separate gold mining legacy sites: Agnew West and Granny Smith. The climate of the sites is relatively dry, but experiences rare heavy rainfall events (Figure 1). Agnew West is a multi-lift WRL occupying 42 hectares. Field and UAV surveys of Agnew West were conducted from 5-9 November 2018. Granny Smith is a two-lift WRL occupying 130 hectares. Field and UAV surveys of Granny Smith were conducted from 2226 November 2018.

\section{Daily Rainfall (mm)}

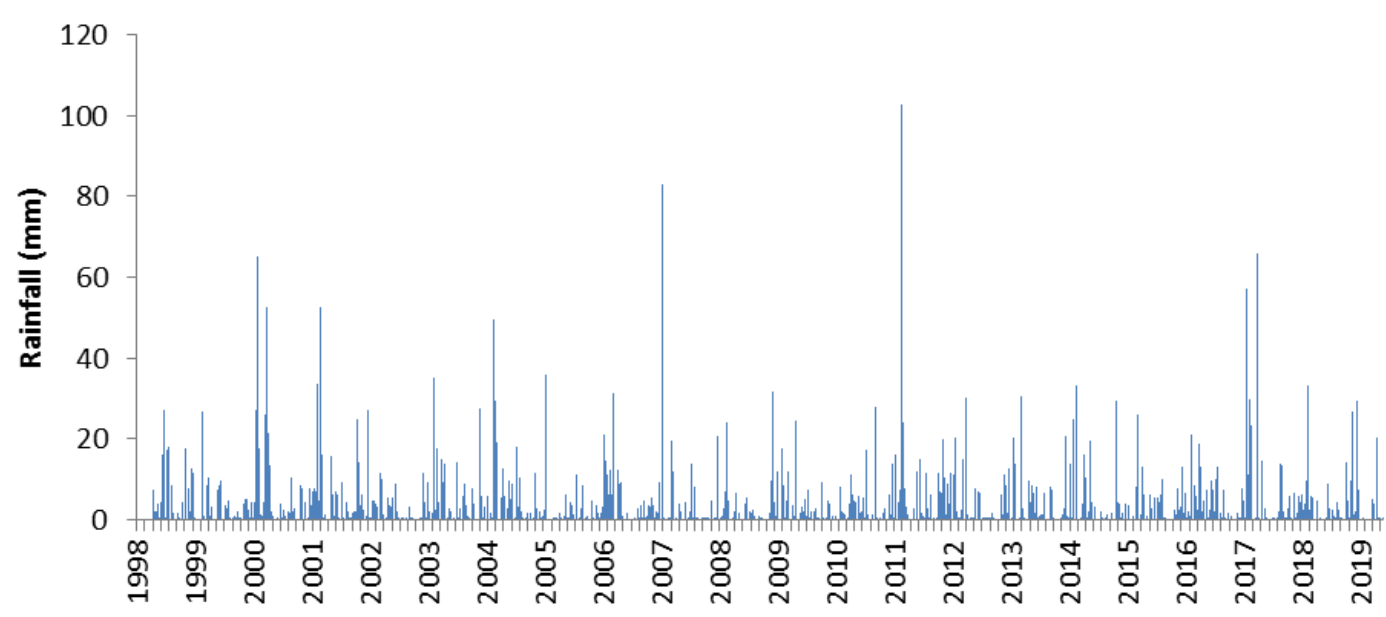

Figure 1 Daily rainfall data for the Agnew West and Granny Smith areas over the previous 20 years

\subsection{Aerial survey}

The aerial surveys were performed with a DJI Inspire 2 multirotor UAV (Figure 2). Data was captured with a DJI X4S camera custom modified to capture green, red and near infrared bands. Ground control points (GCPs) were established across each study site using painted crosses. A total of eight GCPs were placed for Agnew West WRL, while 11 GCPs were place for Granny Smith WRL. In addition to GCPs, spectral calibration targets with spectrally known properties were placed in-scene to assist in data calibration. 


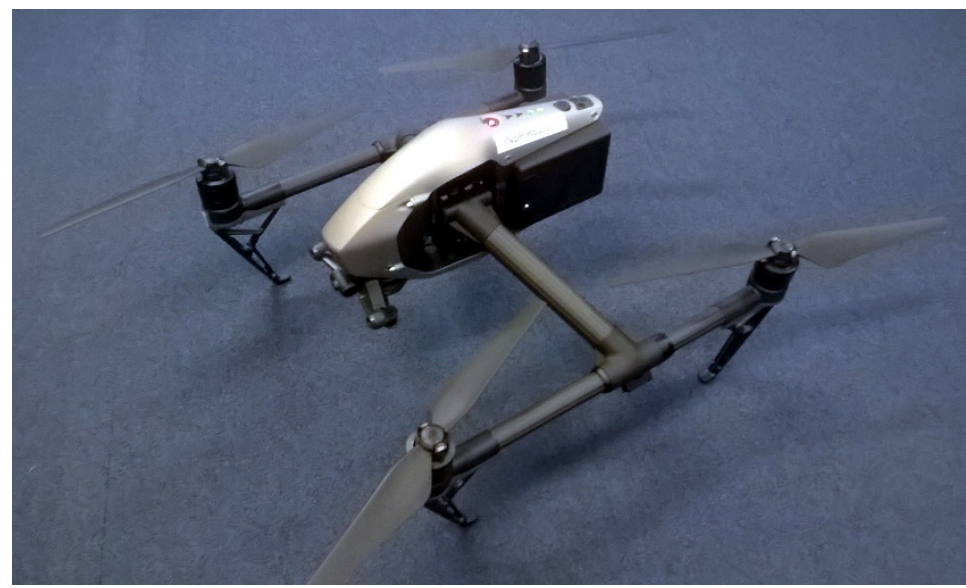

Figure 2 Photograph of the DJI Inspire 2 multirotor unmanned aerial vehicle

\subsubsection{Data preprocessing}

The raw remote sensing data for each site was preprocessed to correct and calibrate the spectral response of the sensor. This was achieved through an empirical line transformation modelled between the known spectral response and the measured sensor response of the radiometric targets. Imagery was spatially aligned, mosaicked and georeferenced using the Agisoft Photoscan photogrammetry software. Root mean square error (RMSE) was used to measure the uncertainty of the photogrammetric products (Table 1). Granny Smith was georeferenced using eight of the 11 points, with the remaining three points serving as check points. Georeferencing of Agnew West utilised five of the eight points and assessed using three check points. The adopted map projection was GDA94 MGA Zone 51, with Australian Height Datum 1972 elevation derived using AUSGEOID09 geoid model.

Table 1 Accuracy assessment of the alignment, mosaicking and georeferencing of the two unmanned aerial data captures: Agnew West and Granny Smith waste rock landforms

\begin{tabular}{lllll}
\hline Image block & $\begin{array}{l}\text { RMSE GCPs } \\
\text { position }(\mathbf{c m})\end{array}$ & $\begin{array}{l}\text { RMSE GCPs } \\
\text { elevation }(\mathbf{c m})\end{array}$ & $\begin{array}{l}\text { RMSE check point } \\
\text { position }(\mathbf{c m})\end{array}$ & $\begin{array}{l}\text { RMSE check point } \\
\text { elevation }(\mathbf{c m})\end{array}$ \\
\hline Agnew West & 0.67 & 0.39 & 1.84 & 3.07 \\
Granny Smith & 0.64 & 0.57 & 2.4 & 1.6 \\
\hline
\end{tabular}

RMSE - root mean square error; GCP - ground control points.

Once imagery for each site was aligned, a dense point cloud was computed using Agisoft Photoscan photogrammetry software. A point cloud consists of individual points, each with an $\mathrm{X}, \mathrm{Y}$ and $\mathrm{Z}$ coordinate that together provides a 3D representation of the site, and is used to estimate the topographic structure of the area. The point cloud was cleansed of vegetation and noise using geometric filters, before a high resolution surface digital elevation model (DEM) was produced. The surface DEM was used as input into the orthoimagery processing, which resulted in an overall image mosaic file.

\subsection{Gully depth and width}

\subsubsection{Ground data collection}

Precise field measurements of gully structure were recorded using a real-time kinematic global satellite navigational satellite system (RTK GNSS) to manually survey gullies at each site. A total of 60 transect profiles were collected from both Agnew West (27 transects) and Granny Smith (33 transects). Each transect was comprised of a series of points (Figure 3 ). The leading and terminating points indicated the outer edges of the gully, while internal points were collected at notable changes in slope. Elevation values 
were then interpolated between the points of each transect to produce an accurate, but generalised, representation of the gully shape.
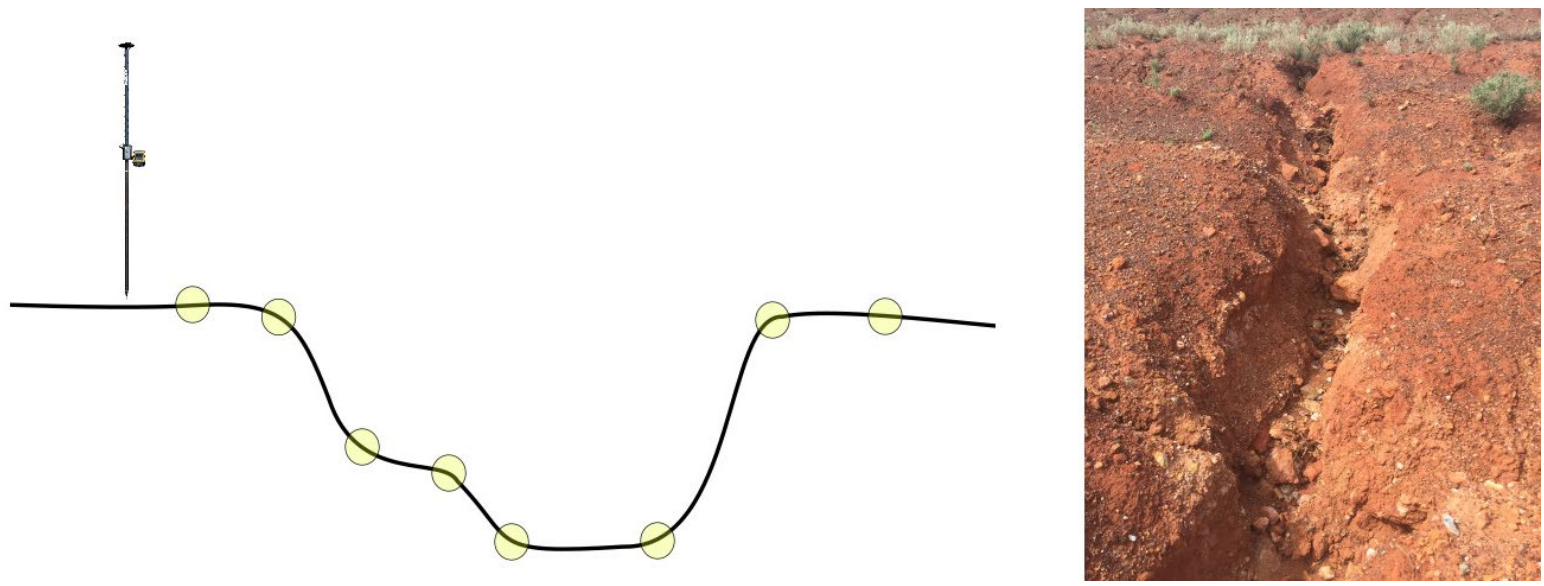

Figure 3 Illustration of a gully profile as recorded by hand using a real-time kinematic global navigational satellite system

\subsubsection{Remote sensing analysis}

Sets of elevation values were extracted from the generated DEM, each spatially corresponding to the location of a defined transect. These sets of elevation values were then transformed into depth measurements by taking the difference of each elevation measure from the maximum elevation within the set.

Gully detection was achieved through a remote sensing analysis that incorporated stochastic modelling of hydrological flows together with the anisotropic integration of local topographic structure. Following detection of the gullies, an iterative multivariate region growing algorithm was then used to demarcate its boundary. A recursive algorithm then reconstructed the pre-erosion surface based upon the derived bounding gully edges. The per-pixel estimation of eroded material was then calculated as the difference between the UAV DEM and the reconstructed surface. A third set of gully depths, which also spatially correspond with the field transect location, was then derived from the gully depth layer.

\subsection{Statistical analysis}

The relationship between gully width and the discrepancy in depth estimated from the DEM and field survey gully depth measurements was examined using linear models. The discrepancy in depth estimates was converted to a percentage of the total depth measured in the field. The relationship between this discrepancy and actual gully depth was then plotted and a curve fitted to the data by minimising the sumsof-squares. The statistical relationship was tested using a linear model which contained site (Granny Smith or Agnew West) as a factor. Model residuals were tested for normality using a Shapiro-Wilk test. All analyses were performed in $\mathrm{R}$ version 3.5.0 (2018-04-23).

\section{Data}

\subsection{Granny Smith waste rock landform}

The generated UAV and topographic data (illustrated as a hillshade model for visualisation) are presented in Figure 4. The locations of transects along with an illustration of the per-pixel estimation of gully extents and depths from the remote sensing analysis, are presented in Figure 5. 

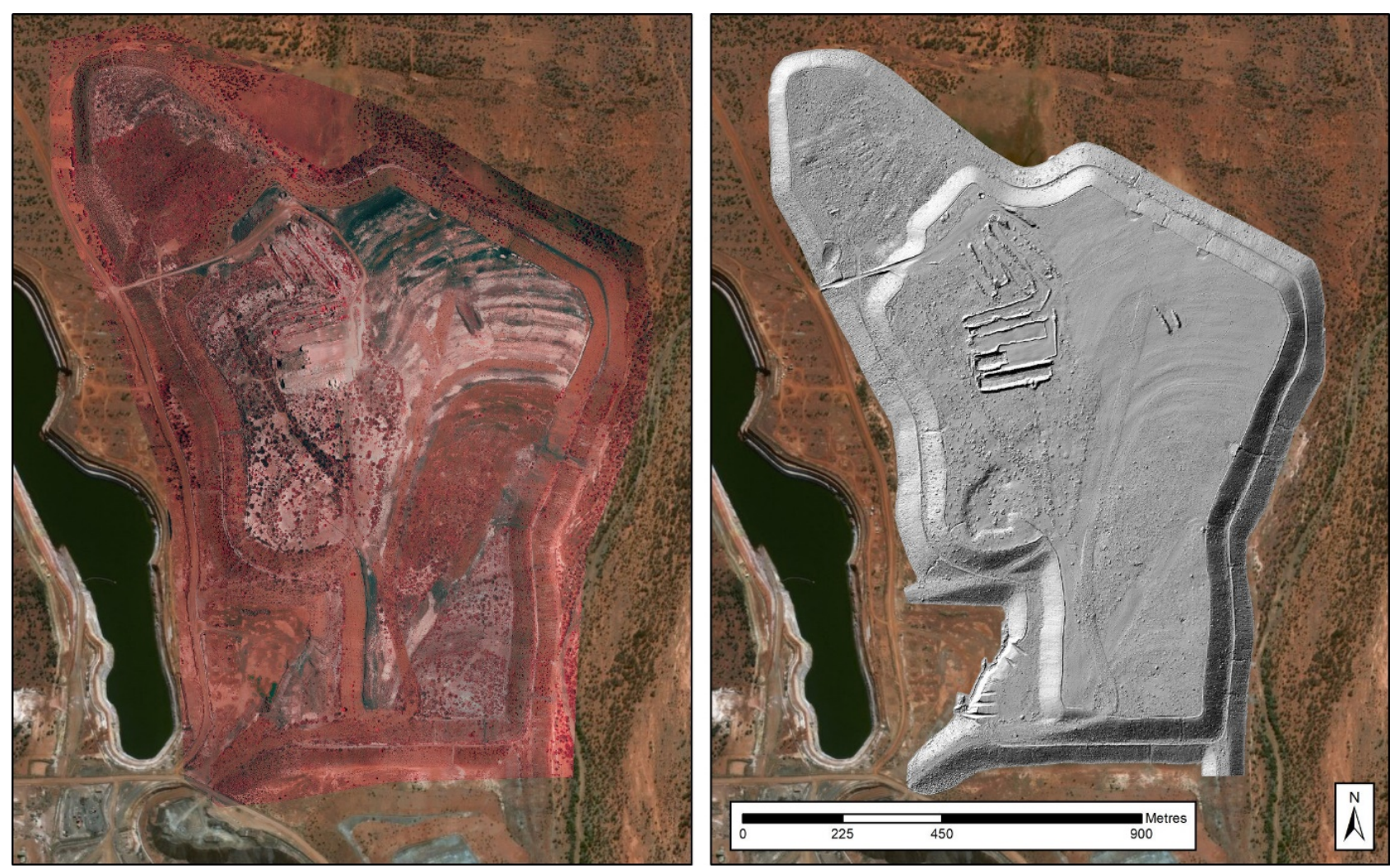

Figure 4 Unmanned aerial vehicle data capture of the Granny Smith waste rock landform (left) and a hillshaded illustration (right) of the derived topographic model
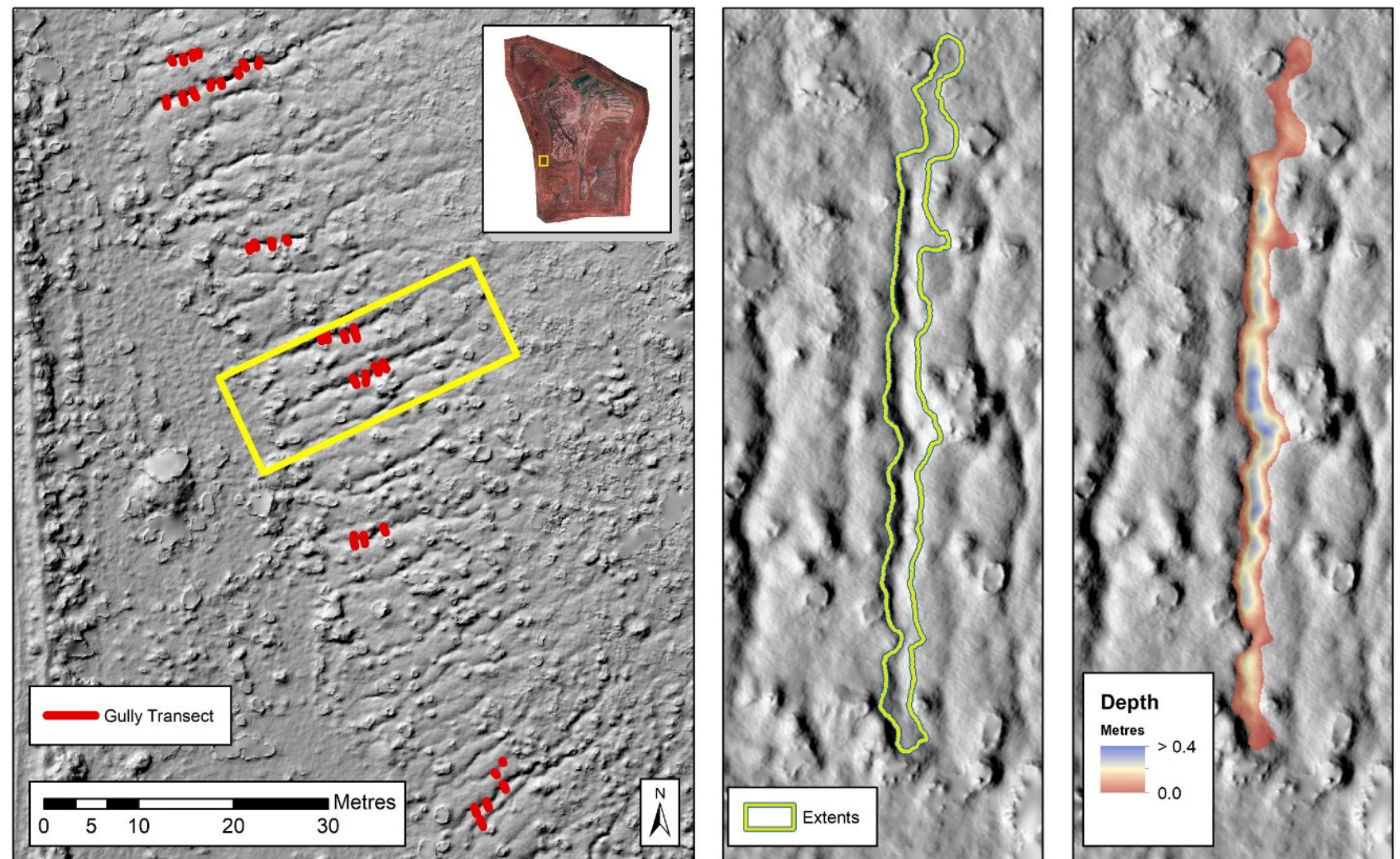

Figure 5 Granny Smith waste rock landform transect location and visualisation of the gully extents and depths derived using remote sensing techniques 


\subsection{Agnew West waste rock landform}

The generated UAV and topographic data (illustrated as a hillshade model for visualisation) are presented in Figure 6. The locations of transects along with an illustration of the per-pixel estimation of gully extents and depths from the remote sensing analysis, are presented in Figure 7.
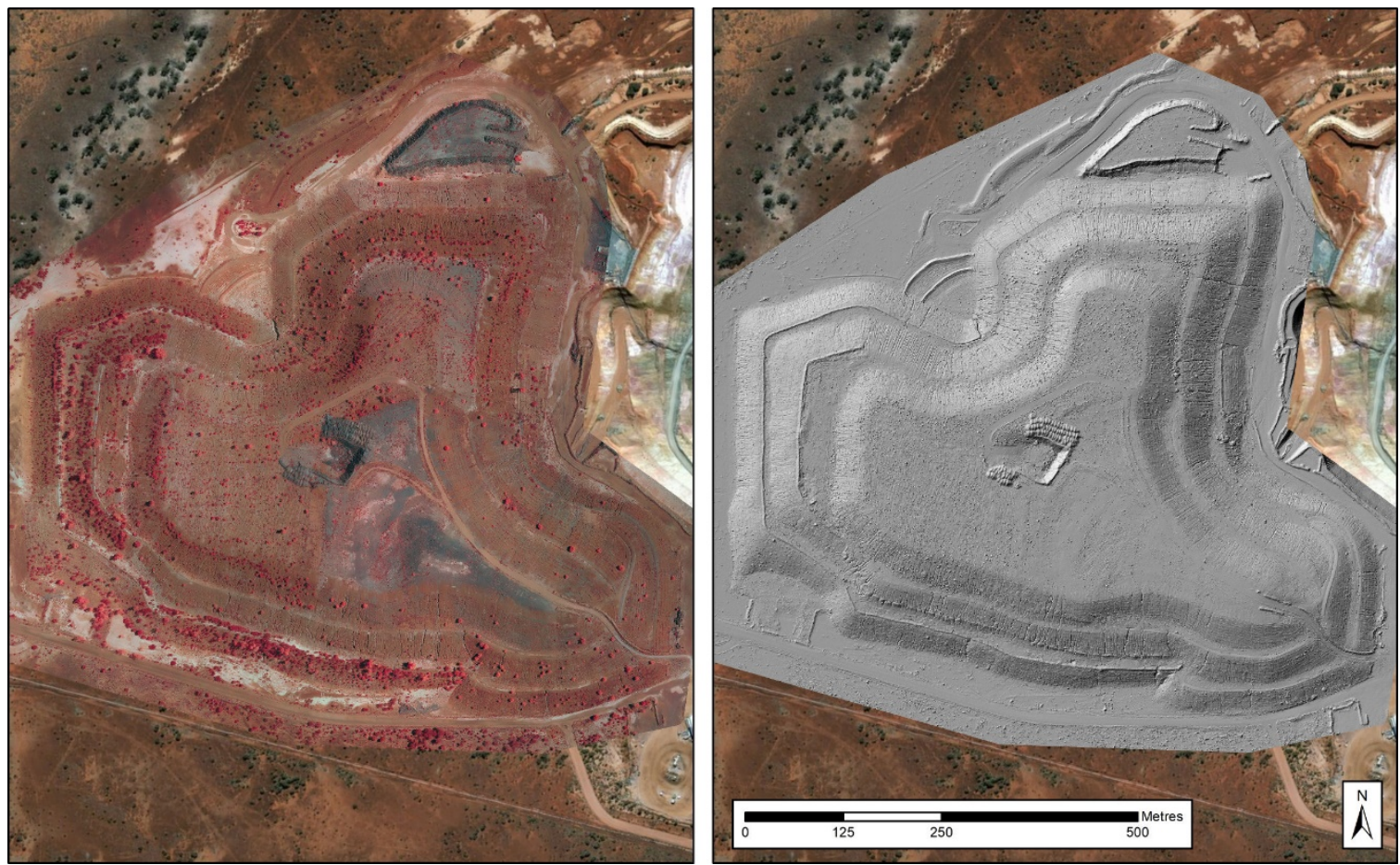

Figure 6 Unmanned aerial vehicle data capture of the Agnew West waste rock landform (left) and a hillshaded illustration (right) of the derived topographic model
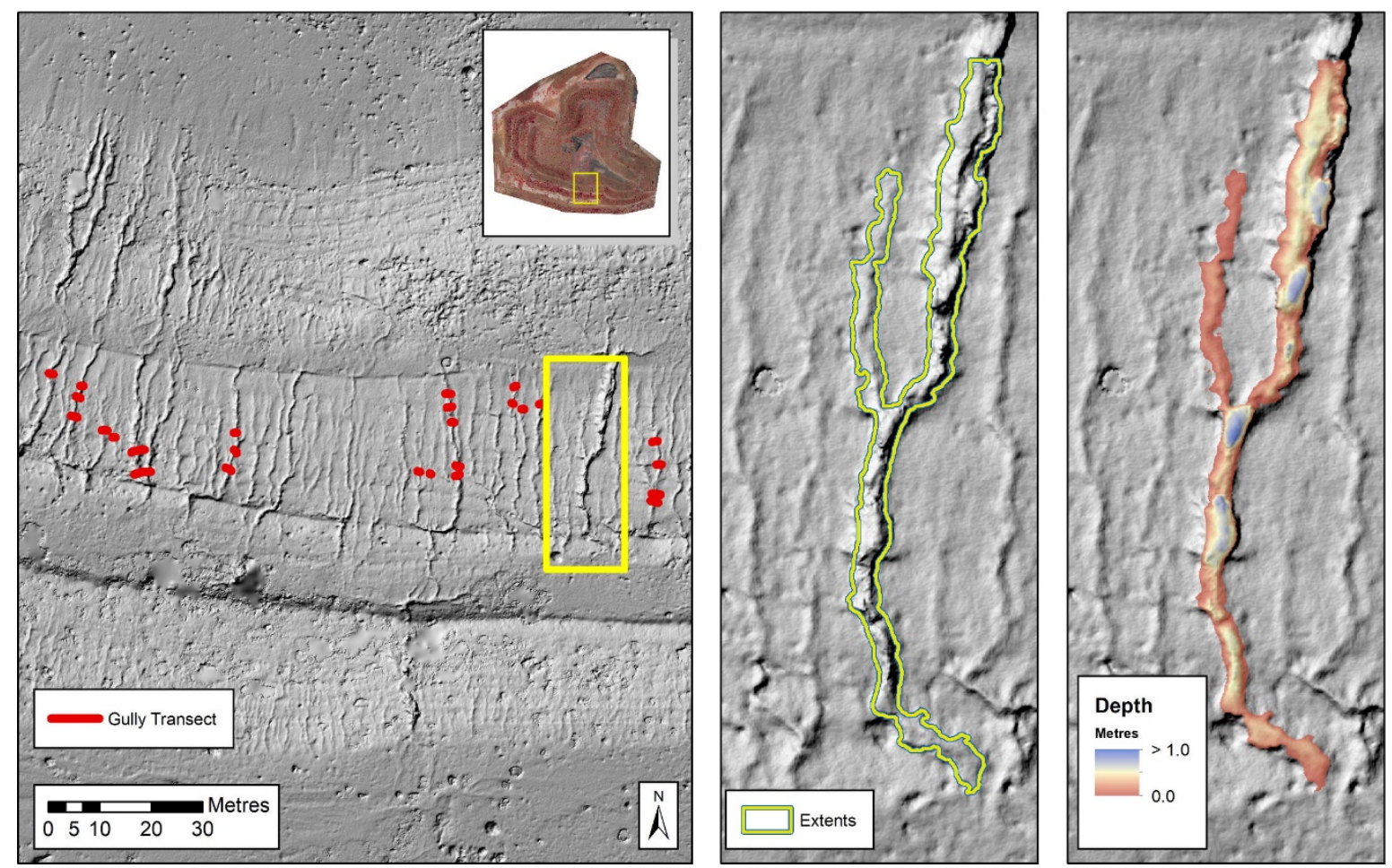

Figure 7 Agnew West waste rock landform transect location and visualisation of the gully extents and depths derived using remote sensing techniques 


\subsection{Depth}

Gully depth and width measurements for each transect were grouped for comparison and analysis (Figure 8). Three sets of depths were derived covering the field survey, the DEM and the remote sensing gully analysis. The two width measurements were derived from the field survey and the remote sensing gully estimation.

\section{Comparison of Gully Depth Profiles}

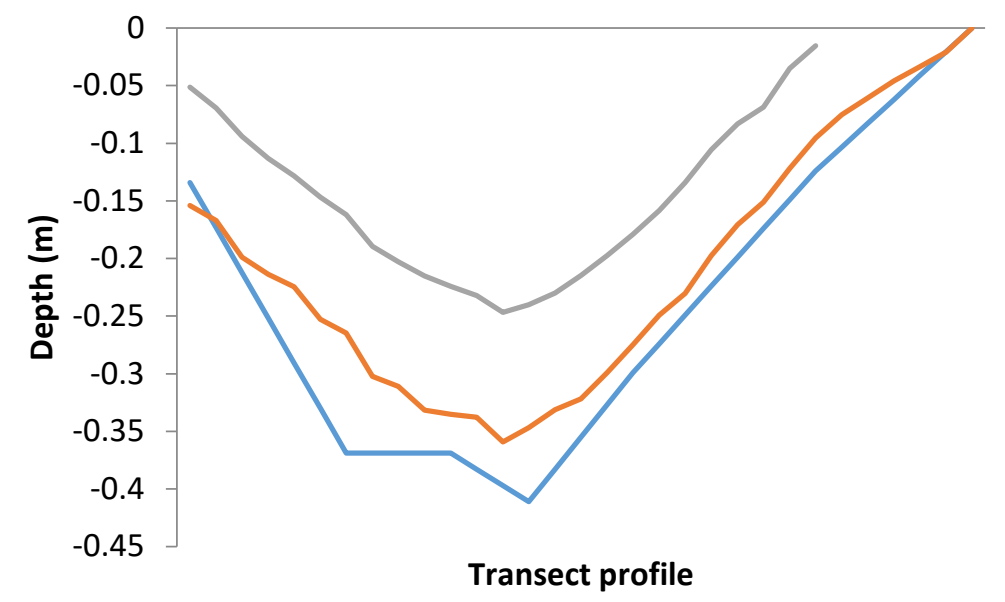

_Field Survey

_ Digital Elevation Model

_ Remote Sensing Analysis

Figure 8 Comparative illustration of gully depth as derived through field survey, digital elevation modelling, and remote sensing gully analysis

\section{$4 \quad$ Results}

The difference in maximum gully depth between the field survey transects and remote sensing analysis is presented for Agnew West in Figure 9 and Granny Smith in Figure 10. Of note is the near universal underestimation of the maximum depth by the remote sensing analysis. An exploration of the difference in gully width between the field survey and remote sensing analysis is presented for Agnew West in Figure 11 and Granny Smith in Figure 12. Of note is the mixture of under and over-estimation of gully widths exhibited in the Agnew West analysis, as compared with the near consistent over-estimation within the Granny Smith analysis.

\section{Agnew West Maximum Depth Error}

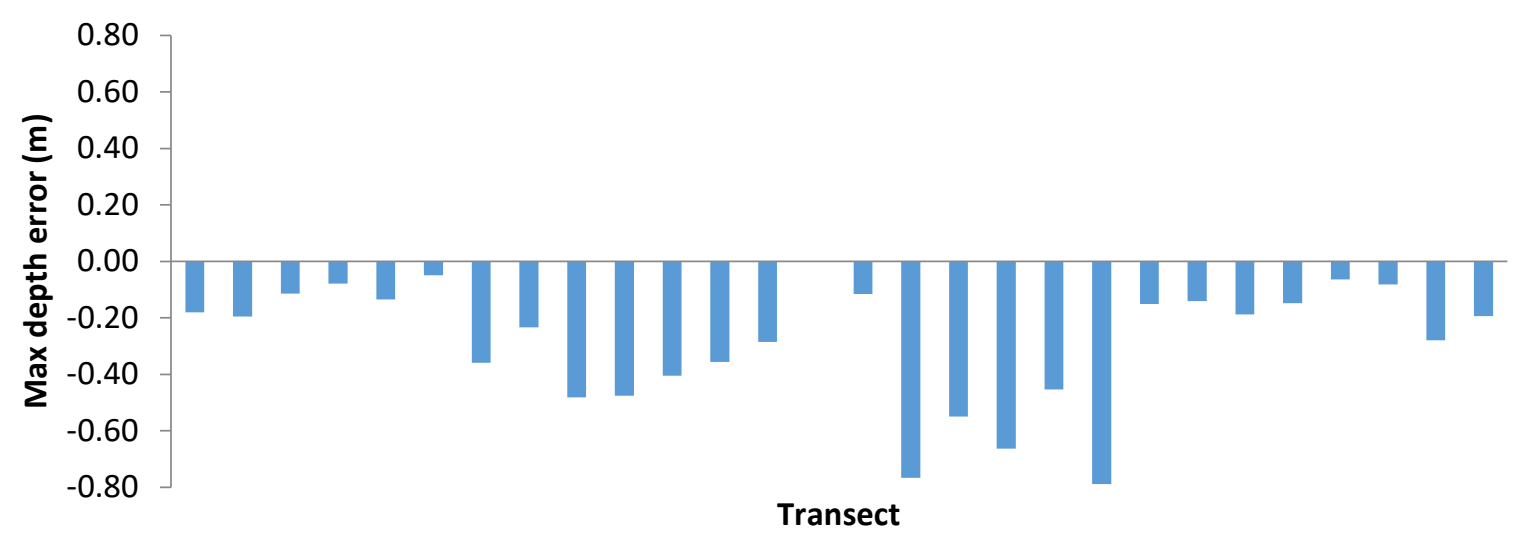

Figure 9 Maximum gully depth error between surveyed and remote sensing analysis for each transect surveyed on Agnew West waste rock landform 


\section{Granny Smith Maximum Depth Error}

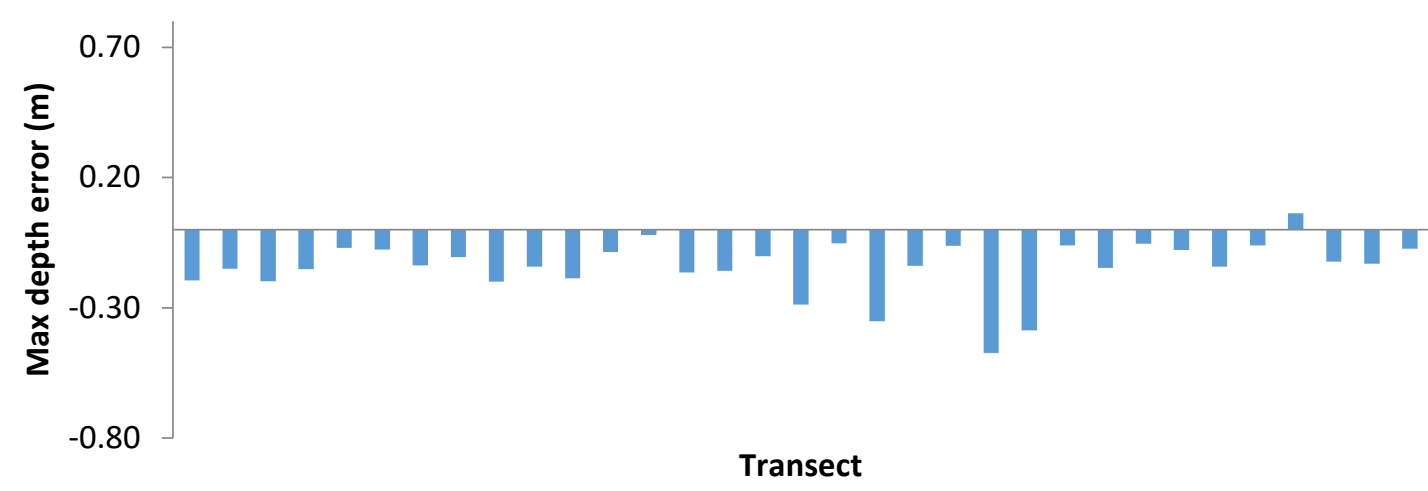

Figure 10 Maximum gully depth error between surveyed and remote sensing analysis for each transect surveyed on Granny Smith waste rock landform

\section{Agnew West Width Error}

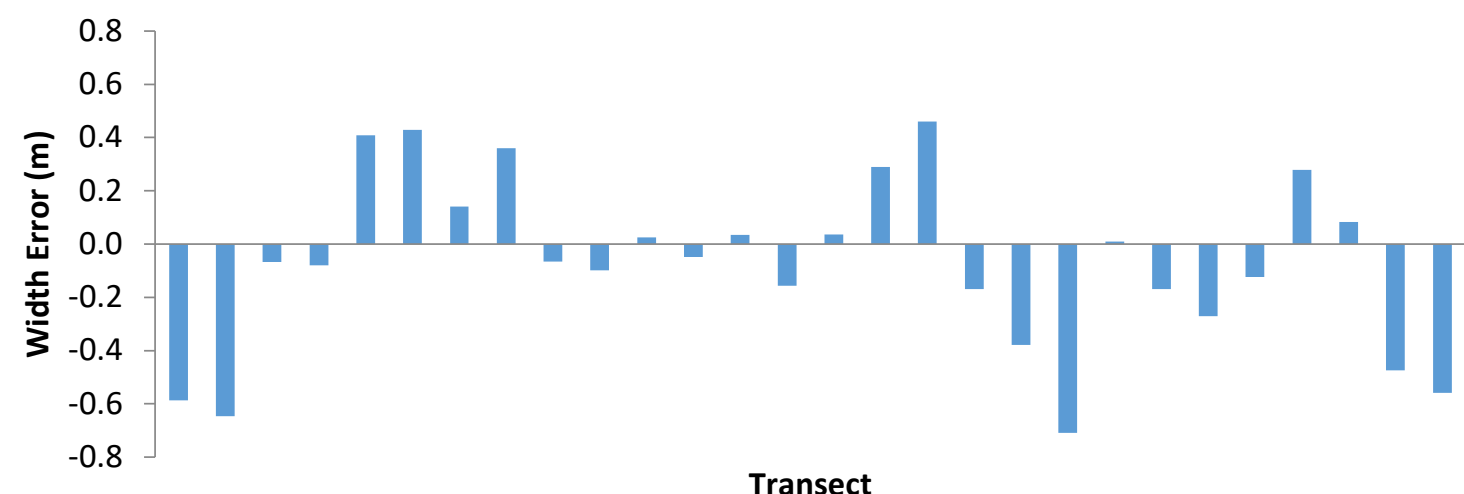

Figure 11 Error in gully width between surveyed and remote sensing analysis for each transect surveyed on Agnew West waste rock landform

\section{Granny Smith Width Error}

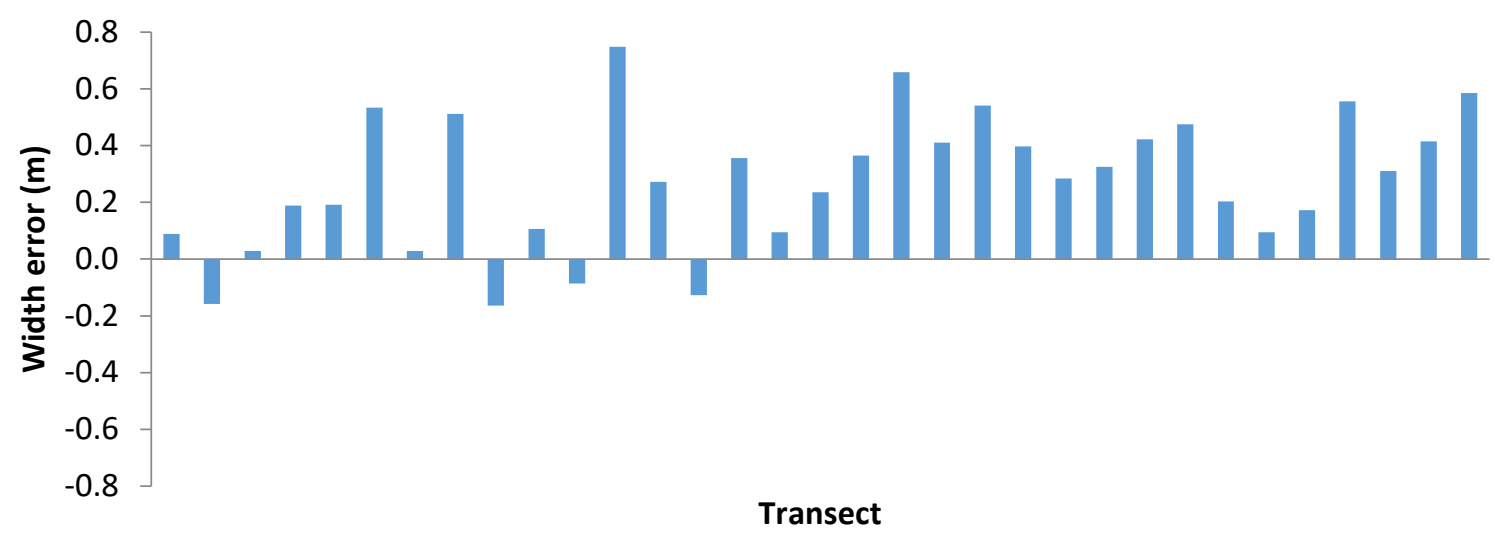

Figure 12 Error in gully width between surveyed and remote sensing analysis for each transect surveyed on Granny Smith waste rock landform 
A significant relationship was found between the width of a gully and the size of the discrepancy between the actual depth and the depth estimated by the $\operatorname{DEM}\left(\mathrm{F}_{1,57}=38.209, \mathrm{P}<0.001, \mathrm{R}^{2}=0.44\right)$. This discrepancy tended to stabilise as the gully width increased (Figure 13). The relationship was best fitted using a log transformation of width and the inclusion of site as factor $\left(F_{1,57}=9.486, P=0.003\right)$. A comparative illustration of this discrepancy between two measured gully profiles is presented in Figure 14.

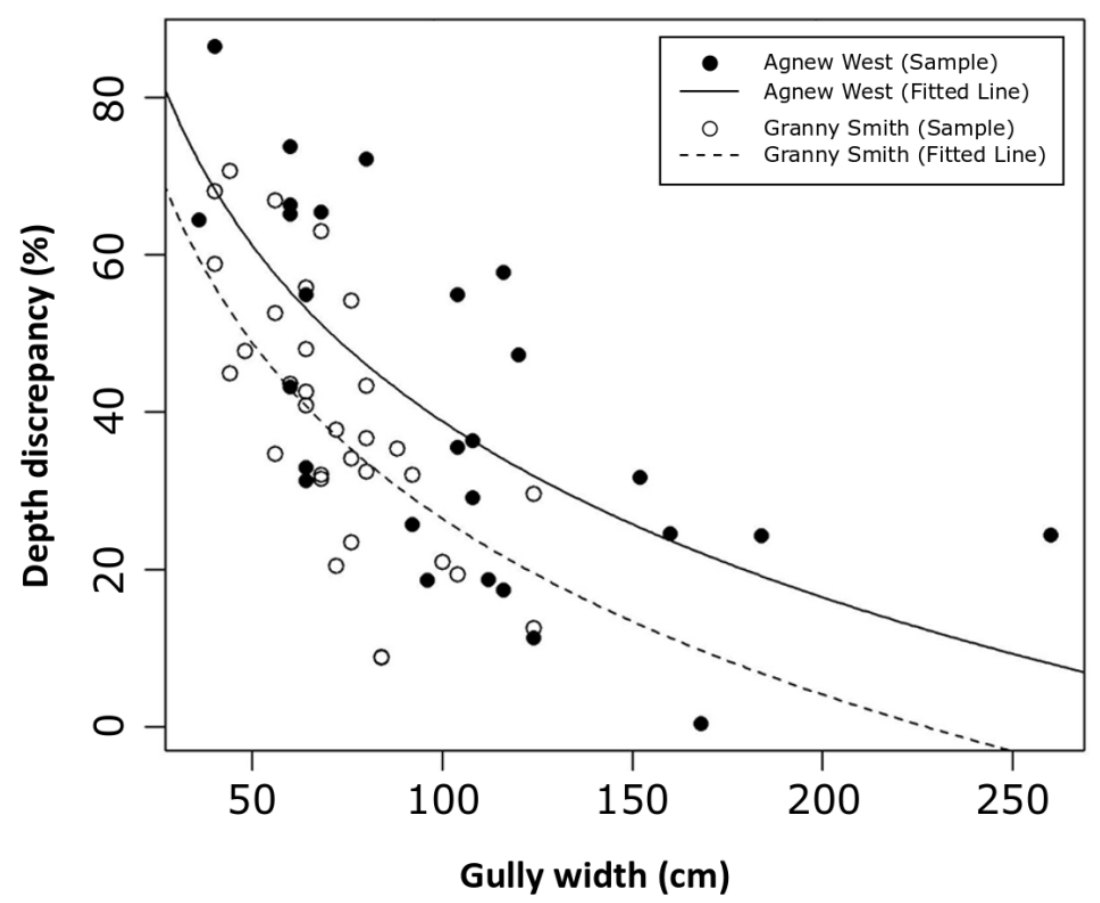

Figure 13 Relationship between the gully width, and the discrepancy between the actual gully depth and the depth estimated from the digital elevation model. The relationship was consistent across both sites

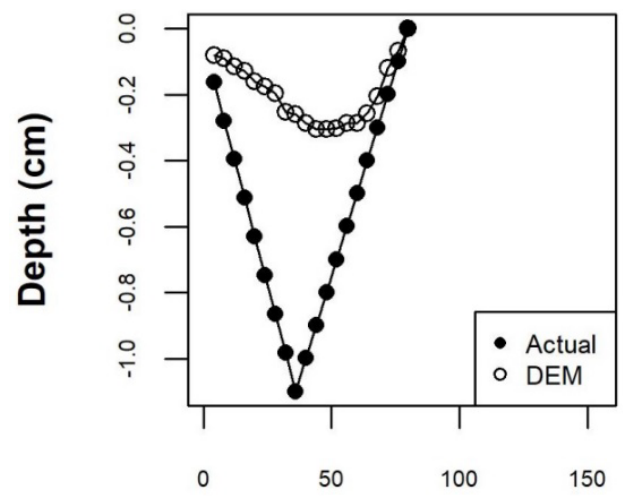

Location (cm)

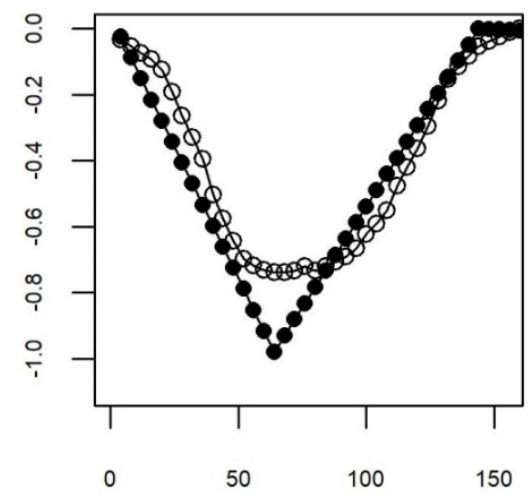

Location (cm)

Figure 14 An example of two gully profiles demonstrating the declining discrepancy between actual gully depth and that estimated by the digital elevation model with increasing gully width

\section{Conclusion}

The results demonstrate that UAV-based remote sensing has the capacity to both detect gullies, as well as estimate parameters, such as gully depth and width, relevant to the monitoring of WRL stability. The general structure of gullying is readily identifiable and allows for an assessment of the broader distribution of gullying across a landform. This provides greater confidence in assessing the formation of gullies across a landform than would be achievable through an extrapolation of a limited number of observations. The fundamental challenge is in the development of an automated, precision delineation of gully boundaries. 
Central to the challenge of automated gully detection is the translation of an abstract conceptual definition of a gully, to sharp real-world boundaries. A gully is defined as a channel carved into the landscape by the movement of water. The estimation of gully extents therefore relies upon examining local topographic properties and predicting potential channels. The difficulty, however, lies in translating the definition of a gully into a logical, quantitative assessment. Gullies may exhibit edges that grade in structure between long smooth transitions to abrupt, sharp drops. Furthermore, a well-defined gully floor may or may not be present. In this regard, defining the edges of gullies using on-ground sampling may have an overtly qualitative component. The translation of this qualitative component to a quantitative assessment remains a significant challenge in this approach. Comparing the results between the two sites shows that Agnew West has greater variation in gully width error, and a greater magnitude of error in the estimated maximum depth error. The Granny Smith WRL exhibits notably lower magnitudes of error in the maximum depth estimations, as well as a more consistent over-estimation of gully width. It was found for both sites that the maximum depth error was near consistently underestimating the depths of gullies. This consistency suggests the potential link between structure and complexity, and the presence of a bias within the model. Potential benefits exist in both the modelling of this factor and its removal to improve the performance of the analysis.

An exploration for this bias factor revealed a significant relationship between the width of a gully and the size of the discrepancy in depth estimation. This manifested as a higher degree of error within narrower gullies, when compared against wider gullies. One potential factor contributing to this phenomenon is the internal structure of gullies, and remote sensing not capturing the gully depth maxima at the scale of image acquisition.

The structure of these gullies is ultimately extracted through the generation of high density point clouds. The size of the gully will affect the number of points that can be extracted and used in its representation. Larger gullies are represented by a large number of points, which in turn allows for the modelling of fine scale structure. Conversely, smaller gullies are represented by a smaller number of points, which will limit the degree of structure that can be modelled.

Differences in point representation are further exacerbated by potential occlusion within narrow but deep gullies. In such conditions, high gully walls may significantly limit the viewing angle of the gully floor. This occlusion may result in an absence of representative points of the gully floor (Figure 15). This leads to the floor being modelled from points extracted from the side of the gully, resulting in an underestimation of the gully floor within the actual DEM. The effect of occlusion represents a source of data error prior to any applied remote sensing analysis.
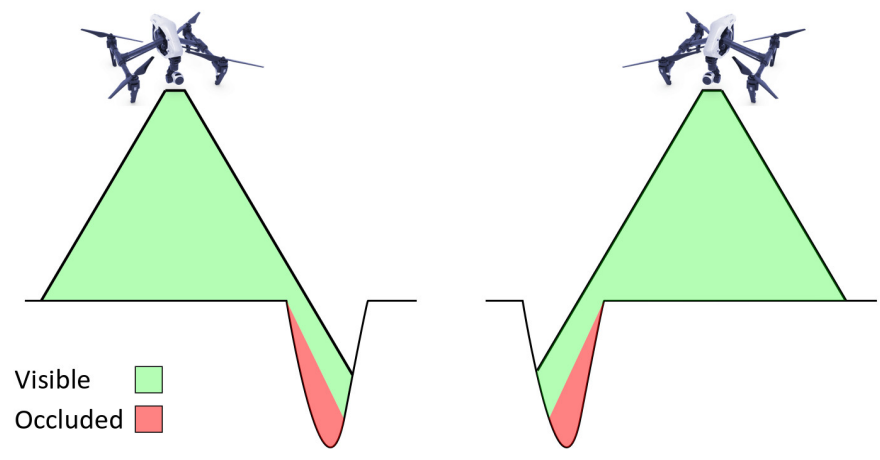

Figure 15 Illustration of gully floor exclusion through the effects of high gully wall occlusion

A fundamental determinate of the remote sensing analysis estimation of gully depth is the calculation of gully width. An over-estimation would be expected to have minimal effects, as changes in elevation would not be as expected beyond the immediate boundary of a gully (Figure 16). Conversely, underestimating width would be expected to result in an underestimation of depth, as the gully edges would not be representative of the true height. Based upon the gully shape, an underestimation of the true width of a gully ultimately results in an underestimation of the overall material lost. It is therefore critical to maximise the estimation of gully width. Fundamental to the estimation of width is demarcation of gully extents. 

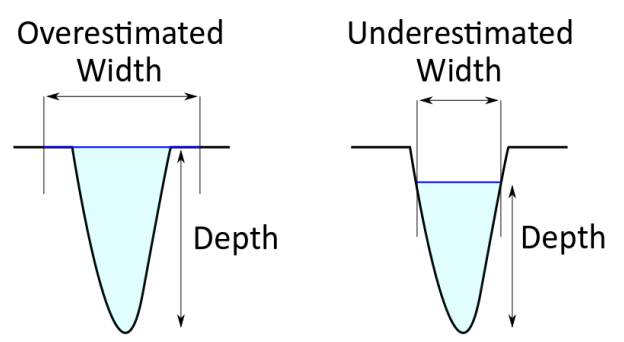

Figure 16 Illustration of the effect of gully width over- and underestimation of gully width upon depth estimation

Regardless of the uncertainty within gully widths and depths as defined by a remote sensing approach, confidence can be placed in the capacity for the algorithm to be applied consistently. This in turn allows for a more confident appraisal of the margin of error within the analysis, as the degree of error can be expected to be consistent. This contrasts against traditional field surveys, whereby measurement error may be an unknown quantity. Furthermore, field survey remains more variable, both within an individual surveyor as their expert knowledge develops, as well as between people that apply subtly different criteria.

Gully formation is of concern for rehabilitation management, as they represent uncontrolled, concentrated water flow. Such concentrated flows have the potential to further erode a landform, undermining its broader stability, as well as acting as a pathway for hazardous materials to leach into the broader environment. The results of this study support the proposal that UAVs, when operated to strict data capture guidelines, have the capacity for quantifying fine scale gully characteristics. The formation of gullies is however, only one aspect of mine site rehabilitation open to monitoring by UAVs. The measurement and monitoring of WRL geometry and vegetative characteristics are also highly feasible with UAVs. The capacity of UAVs to produce an entire census of a site may facilitate the measurement of a range of characteristics important for WRL rehabilitation. With repeated captures, temporal datasets can be constructed and revisited over time to model and map changes in rehabilitation performance. Uncertainty and error are inherent in all measured data, regardless of its source of origin. It is both the consistency and capacity to quantify error within remote sensing data that allows for an empirical assessment of the fitness-for-use, for both the data and corresponding analysis. This increases confidence in both assessing and demonstrating the application of best-practice methodology.

\section{Acknowledgement}

We wish to acknowledge Gold Fields Limited for their valued collaboration in methodology development and data capture, and for the use of their mine sites.

\section{References}

Deng, L, Mao, Z, Li, X, Hu, Z, Duan, F \& Yan, Y 2018, 'UAV-based multispectral remote sensing for precision agriculture: a comparison between different cameras', ISPRS Journal of Photogrammetry and Remote Sensing, vol. 146, pp. 124-136.

Ganci, G, Cappello, A, Bilotta, G, Herault, A, Zago, V \& Del Negro, C 2018, 'Mapping volcanic deposits of the 2011-2015 Etna eruptive events using satellite remote sensing', Frontiers in Earth Science, vol. 6, p. 83.

Guo, Q, Su, Y, Hu, T, Zhao, X, Wu, F, Li, Y \& Zheng, Y 2017, 'An integrated UAV-borne lidar system for 3D habitat mapping in three forest ecosystems across China', International Journal of Remote Sensing, vol. 38, no. 8-10, pp. 2954-2972.

Housman, I, Chastain, R \& Finco, M 2018, 'An evaluation of forest health insect and disease survey data and satellite-based remote sensing forest change detection methods: case studies in the United States, Remote Sensing, vol. 10, no. 8, p. 1184.

Lucieer, A, Turner, D, King, DH \& Robinson, SA 2014, 'Using an unmanned aerial vehicle (UAV) to capture micro-topography of Antarctic moss beds, International Journal of Applied Earth Observation and Geoinformation, vol. 27, pp. 53-62.

Feng, Q, Liu, J \& Gong, J 2015, 'UAV remote sensing for urban vegetation mapping using random forest and texture analysis', Remote Sensing, vol. 7, no. 1, pp. 1074-1094.

Ma, J, Sun, W, Yang, G \& Zhang, D 2018, 'Hydrological analysis using satellite remote sensing big data and CREST model', IEEE Access, vol. 6, pp. 9006-9016.

Zhou, D, Xiao, J, Bonafoni, S, Berger, C, Deilami, K, Zhou, Y \& Sobrino, J 2019, 'Satellite remote sensing of surface urban heat islands: Progress, challenges, and perspectives', Remote Sensing, vol. 11, no. 1, p. 48. 